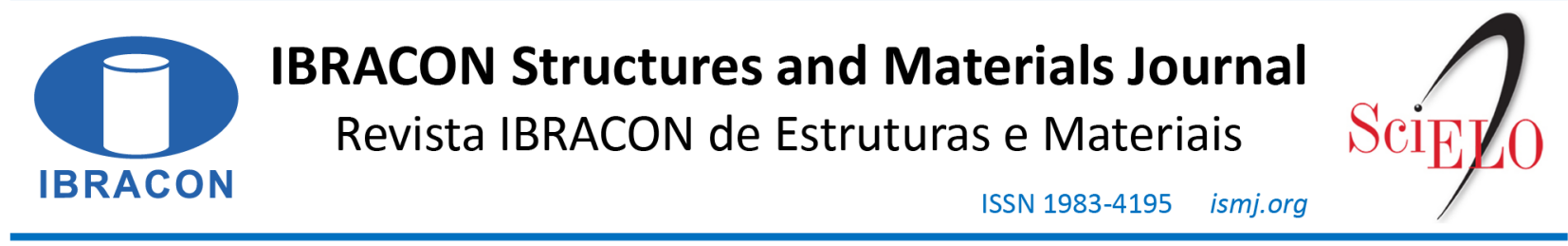

ORIGINAL ARTICLE

\title{
Design considerations on the influence of slab continuity on punching resistance of flat slabs
}

\section{Considerações de dimensionamento sobre a influência da continuidade na resistência à punção de lajes lisas de concreto armado}

\author{
Fernanda Gabriella Batista Santos Oliveira ${ }^{\mathrm{a}}$ (D) \\ Luis Fernando Sampaio Soares ${ }^{\mathrm{a}}$ (D) \\ Robert Lars Vollum ${ }^{\mathrm{b}}$
}

\begin{abstract}
${ }^{a}$ Instituto Federal de Educação, Ciência e Tecnologia do Maranhão - IFMA, Departamento de Construção Civil, São Luís, MA, Brasil ${ }^{\mathrm{b}}$ Imperial College London, Department of Civil and Environmental Engineering, London, UK
\end{abstract}

Received 24 June 2019

Accepted 12 May 2020

\begin{abstract}
This paper assesses the influence of slab continuity on the punching resistance of a realistically proportioned flat slab floor plate without shear reinforcement. The edge column punching resistance of a symmetric flat slab extending bays in each direction was assessed by means of NLFEA with TNO DIANA, MC2010 levels II, III, IV, Eurocode 2 and NBR 6118. Both Eurocode 2 and NBR 6118 are seen to give similar predictions for punching resistance, while MC2010, which is based on the Critical Shear Crack Theory and depends on how rotations are calculated and FE modelling assumptions, varies significantly with its levels of approximation with Level IV agreeing reasonably well with predictions from NLFEA. Direction for the critical rotations is shown to vary and can also be influenced by the reinforcement over the span. For EC2, NBR 6118 and MC2010 LoA II and III punching shear design are independent of span, unlike the results obtained with MC2010 LoA IV.
\end{abstract}

Keywords: punching shear, slab continuity, NBR 6118, Eurocode 2, MC2010.

Resumo: Este artigo avalia a influência da continuidade na resistência à punção de uma laje lisa de concreto armado com dimensões realísticas, sem armadura de cisalhamento. O estudo da resistência à punção teve enfoque em um pilar de borda avaliado por meio de análise não linear em elementos finitos com o TNO DIANA, MC2010 níveis II, III, IV, Eurocode 2 e NBR 6118. O Eurocode 2 e a NBR 6118 apresentaram resultados similares para a resistência à punção, enquanto o MC2010, baseado na Teoria da Fissura Crítica de Cisalhamento, que depende do método de cálculo das rotações e das premissas adotadas de modelagem em elementos finitos, apresentou variações em função dos níveis de aproximação, com o nível IV concordando razoavelmente bem com os resultados provenientes da análise não linear.A direção das rotações críticas também apresentou alterações, possivelmente influenciada pela taxa de armadura ao longo do vão. Para o EC2, NBR 6118 e MC2010 LoA II e III, o dimensionamento à punção independe da continuidade da laje, contrariamente aos resultados obtidos com o nível IV do MC2010.

Palavras-chave: punção, continuidade, NBR 6118, Eurocode 2, MC2010.

How to cite: F. G. B. S. Oliveira, L. F. S. Soares, and R. L. Vollum, "Design considerations on the influence of slab continuity on punching resistance of flat slabs," Rev. IBRACON Estrut. Mater., vol. 13, no. 6, e13615, 2020, https://doi.org/10.1590/S1983-41952020000600015

\section{INTRODUCTION}

Flat slabs are two way spanning slab directly supported by columns. Their thickness is typically governed by deflection control or punching shear resistance. The latter is influenced by many different factors, from concrete and reinforcement parameters, to more complex issues like size effect, slenderness, and boundary conditions (test set up).

Corresponding author: Fernanda Gabriella Batista Santos Oliveira. E-mail: fernandagbso@gmail.com

Financial support: This research was supported by the Science Without Borders Program, through the National Council for Scientific and Technological Development (CNPq) - 237859/2012-2.

Conflict of interest: Nothing to declare. 
It is somewhat understandable that even after more than 100 years of research, and 50 years since the first rational model [1], there is still no consensus regarding a general theory.

The number of models available developed from different backgrounds, such as those described in the literature review of fib [2] (empirical control surface approaches, plasticity approaches, Kinnunen and Nylander [1]-like models, etc.), and dating as early as the 1910s [3], and as late as the 2010s [4], [5], shows that it is a very active field of research, and attempts are still being made in this regard.

The complexity of the phenomenon is reflected in the conflicting opinions expressed by researchers. For instance, depending on the test arrangement, conclusions can become conflicted regarding the influence of continuity, with works such as Sherif and Dilger [6] observing no difference between isolated and continuous specimens, whereas Chana and Desai [7] found an increase of around $40 \%$ on punching resistance from extending the panel beyond the line of contraflexure. The compressive membrane action is well recognized for contributing to punching resistance, which is influenced by a great number of factors leading to difficulties in quantifying the increase in resistance due only to continuity.

fib [2] states that when analyzing isolated specimens, the compressive membrane action is not considered, however in real slabs restrained shrinkage induces tensile stress which reduces the punching resistance. fib [2] also mentions that based on experimental results developed by Sherif [8] it can be concluded that the punching shear strength of an interior slab-column connection in a realistic slab is almost the same for a single column test specimen. Issues like this one led fib [2] to remark that, for design purposes, it is still not recommended to rely on compressive membrane action.

Another example is related to the shear reinforcement layout. Einpaul et al. [9] observed that cruciform and radial arrangements showed comparable performances regarding the punching strength as oppose to Vollum et al. [10], who concluded that stirrups in a cruciform layout increases the shear strength of flat slabs by a multiple up to 1.5 , in comparison to multiples of 2.0 or more for well anchored radial arrangements.

Some of the assumptions of the different mechanical models differ significantly, while presenting reasonable predictions for punching shear capacity. Even models based on similar backgrounds such as the Critical Shear Crack Theory (CSCT) by Muttoni [11] and the Tangential Strain Theory (TST) by Broms [4] can present some discrepancy, like the impact of time dependent effects such as creep and drying shrinkage. The CSCT assumption that the critical shear width is proportional to the slab rotation implicates that punching capacity decreases with time due to the increased rotation resulting from concrete creep and drying shrinkage. However, Broms [4] stated, based on the experimental tests under sustained loading developed by Moe [12], that a slight enhancement of punching capacity (around 4\%) can be observed even though both the width of flexural cracks and deflection increased by $80 \%$. The TST can account for that minor increase by employing a creep factor $(1+\varphi)$ over the critical strain and Young's modulus of its model.

The CSCT by Muttoni [11] and Fernández Ruiz and Muttoni [13] was chosen as the physical theory behind the latest MC2010 [14]. Since its introduction, the model has been tested in many different situations (non-axis-symmetric slabs, steel fibre reinforced slabs, prestressing, post-installed shear reinforcement, continuity, etc.). However, the model is still not universally accepted, and works such as Ferreira et al. [15] and Broms [4] have already identified and discussed a few issues with the theory.

For instance, MC2010 Levels of Approximation (LoA) I to III do not consider the effect of moment redistribution on punching resistance. Consequently, they can give very conservative estimates of the shear resistance of slabs designed in accordance to UK practice using the equivalent frame method, where moments are typically redistributed downwards by $20 \%$ over columns. Both tests and the CSCT suggest that this inward movement of the line of radial contraflexure should lead to an increase in shear resistance. This increase is not accounted for in levels I to III of MC2010 which consequently underestimate the punching resistance of such slabs.

The interpretation of the size effect is also a subject that presents different approaches in normative codes and consequently divergences between researchers. Brazilian and European codes, for example, characterize the size effect through an empirical formulation, whereas MC2010 adopted the size effect equations based on the CSCT. However, Dönmez and Bažant [16] suggest that the CSCT derivation and calculation procedure obfuscates the mechanics of failure not leading to consistent results, based on their experimentally calibrated finite element simulations of crack path and width, of stress distributions and localizations during failure, and of strain energy release.

This paper addresses some of the theoretical issues regarding the punching shear resistance of flat slabs, while giving and comparing the amount of punching shear reinforcement required based on predictions of Brazilian's NBR 6118 [17], Eurocode 2 [18], and MC2010. The discussion is focused on a realistic flat slab according to the model developed by Sherif and Dilger [6], without shear reinforcement, in order to evaluate how the codes of practice consider the influence of in-plane restraint and flexural continuity in punching shear resistance and design. The analysis 
concentrates on edge columns. Punching at edge columns is much less researched than at internal columns, despite the fact that buildings typically have more edge than internal columns. Furthermore, practical experience shows that design for punching shear is frequently more critical at edge than internal columns.

This study also presents an evaluation of the directions of critical rotations for practical slabs, since MC2010 bases the shear resistance on the greater of the rotations about axes normal and parallel to the slab edge. As noted by Soares and Vollum [19] for example, different specimens such as those tested by Regan [20] and El-Salakawy et al. [21] all have shown critical rotations over the longitudinal direction. It also aims to discuss a few modelling assumptions adopted which are relevant on the interpretation of the results, such as the consideration of elastic columns in the numerical analyses required by MC2010 LoA III and IV in order to calculate the punching shear.

\section{CODES OF PRACTICE}

This paper includes comparisons of punching shear requirements between three codes of practice: Eurocode 2 (EC2), NBR6118, and MC2010. This section will provide the equations and general assumptions used in the studies extracted from the codes aforementioned.

\subsection{Eurocode 2}

BS EN 1992, Eurocode 2: Design of concrete structures, commonly abbreviated to EC2, is the current code adopted by the majority of European countries and by a few countries outside Europe. It allows flat slabs to be designed using a proven method of analysis such as Finite Element, Yield Line, Grillage, or Equivalent Frame. The analysis with Equivalent Frame divides the slab in both plane directions into frames consisting of columns and sections of the slab. The panels are divided into column and middle strips. The bending moment should be apportioned for the Column strip as $60-80 \%$ for negative, and $50-70 \%$ for positive moments and as $40-20 \%$ and $50-30 \%$ for negative and positive moments, respectively, in the middle strip. This code locates the control perimeter at a distance $2 \mathrm{~d}$ from the column face and must be calculated in accordance with 6.4.2 section of EC2 [18]. The punching shear resistance without shear reinforcement is given by Equation 1

$V_{R d, c}=0.18\left(100 \rho f_{c k}\right)^{\frac{1}{3}}(1+\sqrt{200 / d}) u d / \gamma_{c}$

where $\rho=\left(\rho_{x l} \cdot \rho_{y l}\right)^{0.5} \leq 0.02$, in which $\rho_{x l}$ and $\rho_{y l}$ are the flexural tension reinforcement ratios $A_{s l} / b d$ within a slab width equal to the column plus $3 d$ to each side. For transfer of moment from slab edge to edge column, EC2 recommends that flexural reinforcement is placed in an effective width of $c_{2}+y$, though an increased width of $c_{2}+2 y$ is commonly adopted in UK practice [22], where $c_{2}$ is the column dimension parallel to the slab edge, and $y$ is the perpendicular distance from the inner column face to the slab edge. $f_{c k}$ is the characteristic concrete cylinder strength, $d$ is the average effective depth of the tension reinforcement. The term $(1+\sqrt{200 / d})$, which accounts for size effect, is limited to a maximum of 2.0 , with $\mathrm{d}$ in $\mathrm{mm}$.

EC2 multiplies the design shear force by $\beta$ to account for the effects of uneven shear due to the support reaction being eccentric. The design shear stress is given by Equation 2 .

$v=\beta \frac{V}{u d}$

EC2 also allows fixed values for $\beta$ for structures where adjacent spans do not differ in length by more than $25 \%$ and the lateral stability does not depend on frame action between the columns and slabs. In such cases, $\beta=1.15$ for internal column, $\beta=1.4$ for edge columns and $\beta=1.5$ for corner columns can be adopted. The required area of shear reinforcement is calculated according to Equation 3

$1.5 A_{s w} \frac{d}{s_{r}} \geq \frac{V-0.75 V_{R d, c}}{f_{y w d, e f}}$ 
where $A_{s w}$ is the area of shear reinforcement in each perimeter, $s_{r}$ is the radial spacing of the shear reinforcement and $f_{y w d, e f}=(250+0.25 d) \leq f_{y w d}$, where $f_{y w d, e f}$ and $f_{y w d}$ are respectively the effective design strength and the design yield strength of the shear reinforcement.

\subsection{MC2010}

MC2010 punching shear recommendations are based on the CSCT [11], [13], and so it relates punching resistance to the rotation in the so-called critical shear crack. The basic control perimeter $u$ is taken at a distance $0.5 d$ from the column face, where $d$ is the effective depth for shear considering support penetration, as illustrated in section 7.3.5.1. of MC2010 [14].

MC2010 reduces the design shear resistance by the multiple $k_{e}$ to account for any eccentricity over the support. MC2010 allows $k_{e}$ to be estimated as 0.9 for inner columns, 0.7 for edge columns and 0.65 for corner columns, for braced frames where the adjacent spans do not differ in length by more than $25 \% . k_{e}$ can also be calculated according to Equation 4

$k_{e}=1 /\left(1+e^{\prime} / b_{u}\right)$

where $e^{\prime}$ is the eccentricity of the shear forces resultant with respect to the centroid of the basic control perimeter, and $b_{u}$ is the diameter of a circle with the same surface as the region inside the basic control perimeter. The punching shear resistance is calculated as $V_{R d}=V_{R d, c}+V_{R d, s}$ where the design shear resistance attributed to the concrete, $V_{R d, c}$, is calculated according to Equation 5

$V_{R d, c}=k_{\psi} k_{e} \frac{\sqrt{f_{c k}}}{\gamma_{c}} u d_{v}$

in which $f_{c k}$ is in megapascals (MPa). The parameter $k_{\psi}$, accounting for the opening of the shear critical crack and its roughness, depends on the maximum rotation $\psi$ of the slab around the support region, and is calculated according to Equations 6 and 7

$k_{\psi}=\frac{1}{1.5+0.9 \psi d k_{d g}} \leq 0.6$

$k_{d g}=\frac{32}{16+d_{g}} \geq 0.75$

where $d_{g}$ is the size of the maximum aggregate particles. For high strength and lightweight concrete, the rupture may occur in the aggregate particles, in which case $d_{g}=0$. The shear resistance provided by transverse reinforcement is calculated as Equation 8

$V_{R d, s}=\sum_{d} A_{s w} k_{e} \sigma_{s w}$

where $\sum_{d} A_{s w}$ is the cross-sectional area of all shear reinforcement within the zone bounded by $0.35 d$ and $\mathrm{d}$ from the border of the support region. $\sigma_{s w}$ is the stress that can be mobilized in the shear reinforcement.

The maximum punching resistance is limited by crushing of the concrete struts near the support region, according to Equation 9. 
$V_{R d, \max }=k_{s y s} k_{\psi} \frac{\sqrt{f_{c k}}}{\gamma_{c}} u d_{v} \leq \frac{\sqrt{f_{c k}}}{\gamma_{c}} u d_{v}$

The coefficient $k_{s y s}$ accounts for the performance of punching shear reinforcing systems, and is taken as 2.4 for stirrups and 2.8 for studs, provided the radial spacing to the first perimeter of shear reinforcement from the column face $s_{o}$ is $\leq 0.5 d$ and the spacing of successive perimeters of shear reinforcement $s_{1}$ is $<0.6 d_{v}$.

LoA II calculates the rotations as Equation 10

$\psi=\alpha \frac{r_{s}}{d} \frac{f_{y d}}{E_{s}}\left(\frac{m_{E d}}{m_{R d}}\right)^{1.5}$

where $r_{s}$ denotes the position where the radial bending moment is zero with respect to the column axis and can be approximated as $0.22 L_{x}$ or $0.22 L_{y}$ if $0.5 \leq L_{x} / L_{y} \leq 2.0, f_{y d}$ is the design yield strength of the flexural reinforcement, $E_{s}$ is the modulus of elasticity of reinforcement, $\alpha=1.5, m_{R d}$ is the design average flexural strength per unit width of the support strip, and $m_{E d}$ is the average bending moment per unit width in the support strip, which is assumed to be of width $b_{s}=1.5 \sqrt{r_{s, x} \cdot r_{s, y}} \leq L_{\min }$. In LoA III, $\alpha$ from Equation 10 can be taken as 1.2, provided that both $m_{E d}$ and $r_{s}$ are calculated with linear elastic finite-element analysis (LFEA), though $r_{s}$ should not be taken as less than $0.67 b_{s r}$ at edge and corner columns. Although not stated in MC2010, to account for twisting moments the reinforcement should be designed for the Wood moments [23] or equivalent.

Level IV of approximation allows the rotation $\psi$ to be calculated with a nonlinear finite element analysis of the structure (NLFEA), accounting for tension stiffening, cracking, yielding of reinforcement, and any other significant non-linear effect that would help improving the simulation of the structure and its behaviour.

\subsection{NBR 6118}

Punching shear requirements according to Brazilian code NBR 6118 are very similar to those of EC2, previously described in section 2.1. Like EC2, the Brazilian code allows the use of equivalent frame method for the design of flat slabs when it is a reinforced concrete slab, in which the columns are arranged in regular orthogonal rows and with slightly different spans. The Brazilian code also locates the control perimeter at a distance $2 \mathrm{~d}$ from the column face, as presented in section 19.5.2 of NBR 6118 [17]. The proportion of punching shear assumed to be resisted by concrete is calculated according to Equation 1. This portion is also reduced when shear reinforcement is considered, leading to Equation 11.

$1.5 A_{s w} \frac{d}{s_{r}} \geq \frac{\left\{V_{S d}-0.10\left[\left(100 \rho f_{c k}\right)^{\frac{1}{3}}\left(1+\sqrt{\frac{200}{d}}\right)\right]\right\} u_{1} d}{f_{y w d, e f}}$

However, the size effect term of $(1+\sqrt{200 / d})$ is not limited to a maximum of 2.0, nor the flexural tension reinforcement ratio to a limit of $2 \%$ as recommended by EC2. NBR 6118 does not allow the use of fixed values, such as $\beta$ (EC2) and $k_{e}$ (MC2010), to account for eccentricity over the support in any circumstances, as opposed to the others codes under analysis. Therefore, the design shear stress is calculated based on Equation 12

$v=\frac{V}{u^{*} d}+\frac{M_{S d l} k}{W_{p} d}$

Where $u^{*}$ denotes the reduced control perimeter, $k$ is a parameter dependent on the ratio between the column dimensions and provides the transferred moment to the column in punching shear, $W_{p}$ is the plastic resistance module 
of the control perimeter and $M_{S d l}$ the design moment transferred from the slab to the edge column in the plane perpendicular to the free edge.

\section{GENERAL ASPECTS}

In order to assess the impact of continuity, a representative flat slab was designed using the equivalent frame method. The floor plate is $250 \mathrm{~mm}$ thick and consists of 9 square bays spanning $7500 \mathrm{~mm}$ between column centrelines. The internal columns are $400 \mathrm{~mm}$ square in cross section. Edge and corner columns are $250 \mathrm{~mm} \times 400 \mathrm{~mm}$ in cross section. Figure 1 shows a plan view of the slab which, although not shown, is considered to be braced with shear walls or steel bracing. The slab was designed for a single load case of all spans fully loaded as permitted by the UK National annex to EC2 [24]. The resulting support bending moments were redistributed downwards by $30 \%$ at the edge columns and $20 \%$ at internal columns as required by the UK National annex to EC2 when designing for a single load case.

The characteristic concrete cylinder and reinforcement yield strength were taken as $f_{c k}=30 \mathrm{MPa}$ and $f_{y k}=500 \mathrm{MPa}$, respectively. The design loadings were slab self-weight $=6.25 \mathrm{kN} / \mathrm{m}^{2}$, superimposed dead load $=1.5 \mathrm{kN} / \mathrm{m}^{2}$, imposed load $=2.5 \mathrm{kN} / \mathrm{m}^{2}$ and a perimeter load of $10 \mathrm{kN} / \mathrm{m}$ for external cladding.

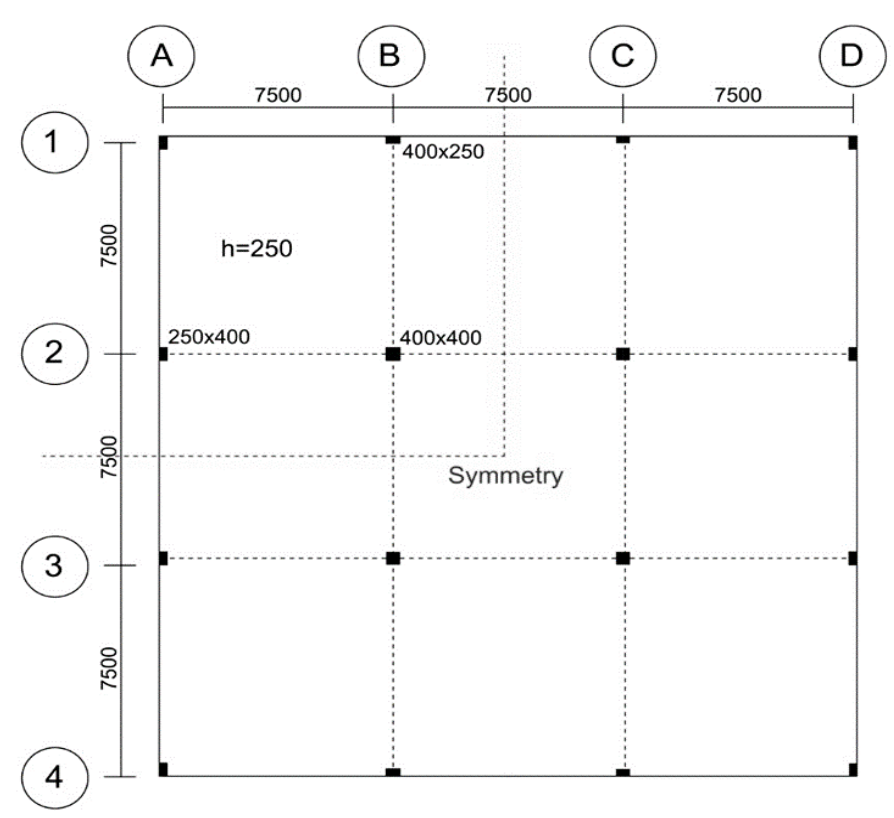

Figure 1. Plan view of the considered flat slab (Dimensions in $\mathrm{mm}$ ).

The resulting uniformly distributed design ultimate load, calculated with load factors of 1.35 for dead load and 1.5 for imposed load, is $14.21 \mathrm{kN} / \mathrm{m}^{2}$. The hogging flexural reinforcement was designed for the peak bending moments at the centreline of the columns. The slab was divided into column and middle strips and the design bending moments were proportioned between the strips in percentage as 75:25 for hogging, and 55:45 for sagging moments as allowed by the EC2 and NBR 6118 . The additional reinforcement required by the cladding load was distributed across the entire edge column panel width in the same proportion as the UDL (Uniformly Distributed Load).

Surplus span rebar was provided for deflection control in accordance to EC2 span-to-effective-depth rules, which, for instance, increased the column strip sagging reinforcement ratio between columns A2 and B2 (refer to Figure 1) from $0.51 \%$ to $0.73 \%$, or its middle strip sagging from $0.41 \%$ to $0.45 \%$. Two thirds of the hogging reinforcement within the column strip was placed within a band over the columns of $1 / 4$ of the panel width. Details of the flexural reinforcement can be found in Soares [25]. The reinforcement effective depths were $d_{1}=212 \mathrm{~mm}$ and $d_{2}=196 \mathrm{~mm}$, calculated assuming $30 \mathrm{~mm}$ cover and $16 \mathrm{~mm}$ bars in both directions. A minimum area of $377 \mathrm{~mm}^{2} / \mathrm{m}$ was provided, calculated in accordance with EC2 as $0.0013 b_{t} . d$, where $b_{t}$ is the width of the tension zone. No shear reinforcement was designed at this stage, as a comparative study focusing on this parameter is carried out later on. 


\section{CONTINUOUS SLABS OF SHERIF AND DILGER [6]}

Sherif and Dilger [6] tested two continuous flat slabs with a novel setup in which the panel extended to the points of zero shear, as shown in Figure 2. Further details of the test set up are given in Sherif [26]. The slabs measured 5000 $\mathrm{mm} \times 7500 \mathrm{~mm}$ on plan and were $150 \mathrm{~mm}$ thick. Both slabs had the flexural reinforcement depicted in Figure 3, with No. 15 bars $\left(200 \mathrm{~mm}^{2}\right)$ with $f_{y}=444 \mathrm{MPa}$, and No. 10 bars $\left(100 \mathrm{~mm}^{2}\right)$ with $f_{y}=523 \mathrm{MPa}$. Slab S2 was reinforced with shear studs at both interior and edge columns in the arrangement shown in Figure 4. Slab S1 had no shear reinforcement.

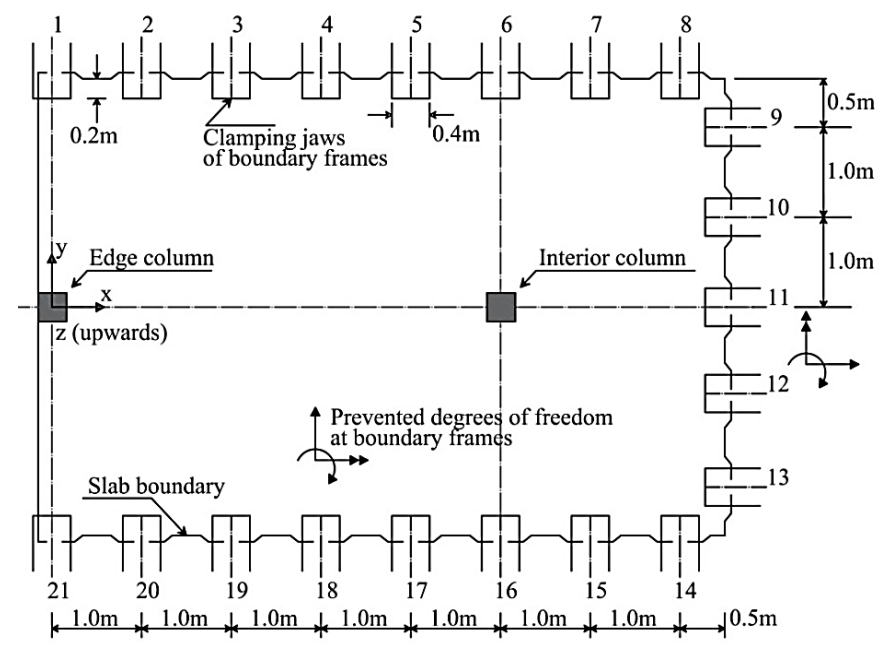

Figure 2. Specimen tested by Sherif and Dilger [6].

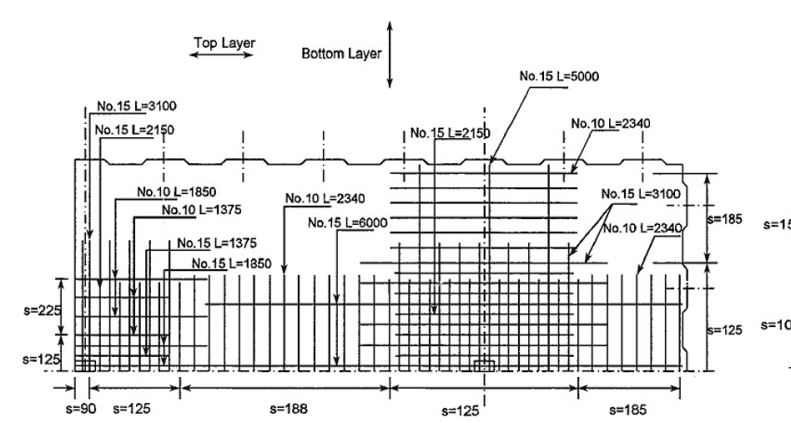

(a)

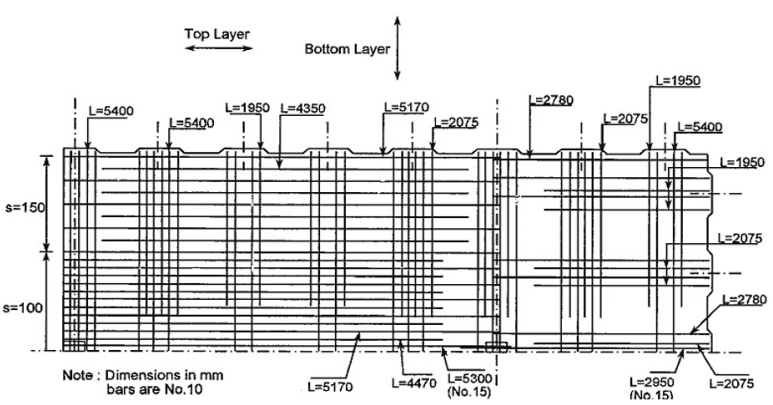

(b)

Figure 3. Flexural reinforcement for the specimens tested by Sherif and Dilger [6].
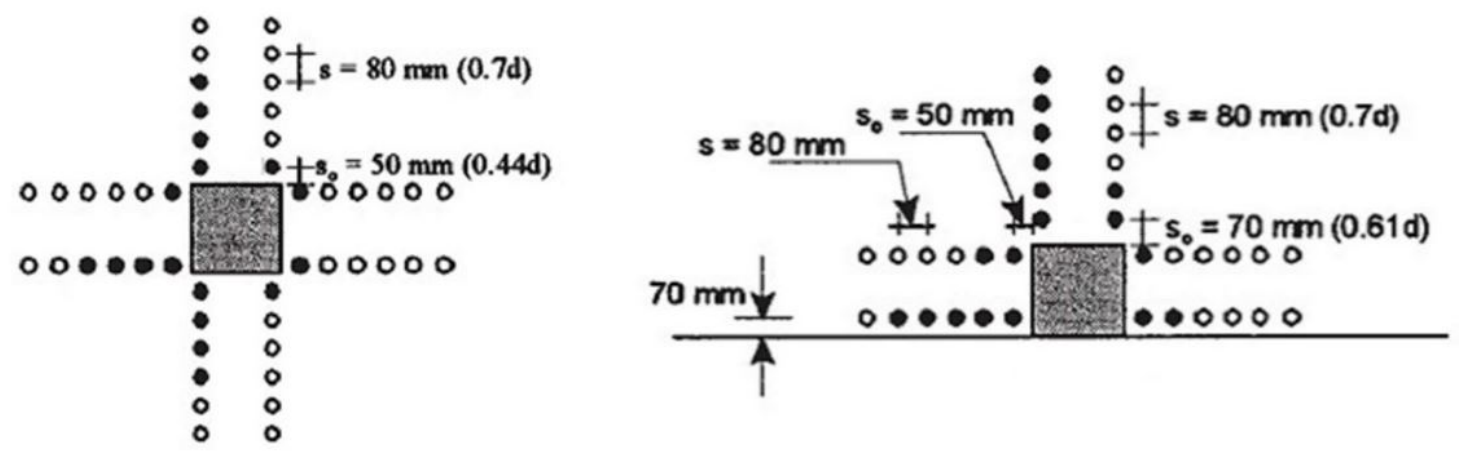

Figure 4.Shear reinforcement for slab S2 of Sherif and Dilger [6]. 
The load was applied to the specimen at 16 points on the full panel and 8 points on the half panel to simulate an UDL. The columns extended $1.5 \mathrm{~m}$ (around half of the story height) above and below the slab and were heavily reinforced with six No. $25\left(500 \mathrm{~mm}^{2}\right)$ deformed bars. Table 1 gives more details of the specimens.

Table 1. Details of specimens tested by Sherif and Dilger [6].

\begin{tabular}{|c|c|c|c|c|c|c|c|c|c|}
\hline Slabs & $\begin{array}{c}\text { Column size } \\
\text { (edge and } \\
\text { internal) } \\
(\mathrm{mm})\end{array}$ & $\mathbf{h}(\mathbf{m m})$ & d (mm) & $\begin{array}{c}\rho_{c 2+3 h}{ }^{*} \\
\mathbf{\%}\end{array}$ & $\mathbf{f}_{\mathrm{c}}(\mathbf{M P a})$ & $\begin{array}{c}\text { Failure } \\
\text { Load } \\
\left(\mathbf{k N} / \mathbf{m}^{2}\right)\end{array}$ & $\begin{array}{l}\text { Failure } \\
\text { Mode and } \\
\text { Location }\end{array}$ & $\begin{array}{c}\text { Failure } \\
\text { Shear } \\
\text { Force }(k N)\end{array}$ & Remarks \\
\hline S1 & $250 \times 250$ & 150 & 114 & 1.41 & 28 & 15.54 & $\begin{array}{l}\text { Punching at } \\
\text { internal } \\
\text { column }\end{array}$ & 399 & $\begin{array}{l}\text { No Shear } \\
\text { Studs }\end{array}$ \\
\hline S2 & $250 \times 250$ & 150 & 114 & 1.41 & 33 & 19.97 & $\begin{array}{l}\text { Punching at } \\
\text { edge column }\end{array}$ & 164 & $\begin{array}{l}\text { Studs at edge } \\
\text { and internal } \\
\text { column }\end{array}$ \\
\hline
\end{tabular}

*: Reinforcement ratio within the width $\mathrm{c} 2+3 \mathrm{~h}$

\subsection{Numerical Modelling}

The Sherif and Dilger [6] slabs were analysed with TNO Diana version 9.6 [27] using the following modelling assumptions: the slab was modelled with the eight-node quadrilateral isoparametric curved shell element. Reinforcement bars were modelled as embedded elements. The Von Mises yield criterion was adopted for reinforcement with no hardening. The integration scheme was $3 \times 3$ in plan with 9 points through the slab thickness as recommended by Vollum and Tay [28]. Concrete was modelled using the 'total strain fixed crack model' of Diana. Following the suggestion of Vollum and Tay [28], the concrete tensile was taken as $0.5 f_{c t}$, where $f_{c t}$ is the mean indirect tensile strength. Linear tension softening was adopted in which the tensile stress reduced to zero at a strain of $0.5 \varepsilon_{y}$, where $\varepsilon_{y}$ is the reinforcement yield strain.

Diana adopts the concept of a shear retention factor in its Total Strain Fixed crack models to account for the reduction in shear stiffness after cracking. Suidan and Schnobrich [29] suggests that it should lie around 0.1 0.2, which gives good results for shear dominant failure cases as shown in Sagaseta [30]. Trautwein [31], also using the commercial software Diana, developed analyses in axisymmetric models of slabs used in experimental studies, with a shear retention factor equal to 0.2 . The value adopted for the shear retention factor in this analysis was also 0.2 .

For behaviour in compression, the Thorenfeldt model [32] was adopted along with the four-parameter Hsieh-TingChen failure surface to simulate the increase in concrete compressive strength with increasing isotropic stress. Concrete compressive strength reduction due to lateral cracking was modelled in accordance with Vecchio and Collins [33]. A Quasi-Newton iterative solution procedure was adopted in conjunction with an energy-based convergence criteria with $10^{-4}$ tolerance. The main aim of the NLFEA was to capture the deflected shape of the slab, allowing the punching resistance to be calculated with MC2010 LoA IV.

Around the columns, the mesh was refined using $50 \mathrm{~mm}$ square eight-node quadrilateral curved shell elements compared with $100 \mathrm{~mm}$ square elements elsewhere. The connection between the refined and coarse mesh was made with six-node triangular curved shell elements, shown in Figure 5. The final mesh is presented in Figure 5. The columns were modelled with the twenty-node brick and element size of $100 \times 50 \times 50 \mathrm{~mm}$.

Figure 6 compares deflections from test data of Sherif [26] and NLFEA. The deflected shape was extracted along the slab centreline in the $7500 \mathrm{~mm}$ direction (Longitudinal), and the displacement was extracted at midway between the edge and internal column. Both slabs are reported to have failed in punching shear. The NLFEA gave very good estimates of the measured slab deflections up to failure. The analysis of S1 stopped fairly close to the flexural capacity as indicated by the yield line capacity in Figure 6 .

Sherif and Dilger [6] reports that specimens S1 and S2 failed in punching at the internal and edge column, respectively. Figure 7 shows the prediction of MC2010 LoA IV, with resistances calculated from Equations $5\left(V_{R d, c}\right)$ and Equation $8\left(V_{R d, s}\right)$ using a $k_{e}=0.9$ and $k_{e}=0.7$ for internal and edge columns, respectively. 


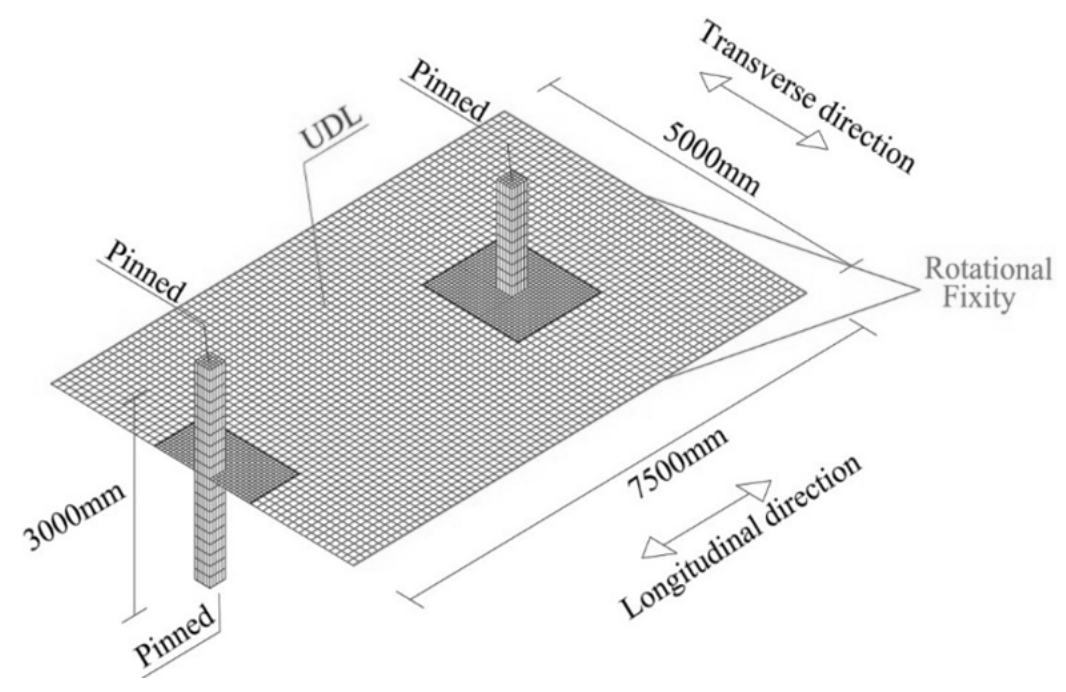

Figure 5. Mesh used for the NLFEA of Sherif and Dilger's [6] tests.

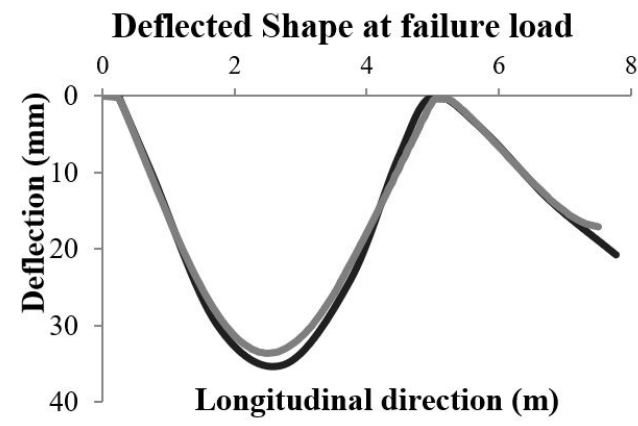

Deflected Shape at failure load

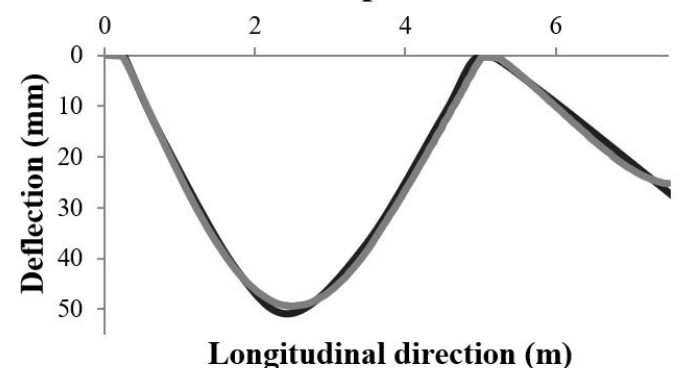

Longitudinal direction (m)

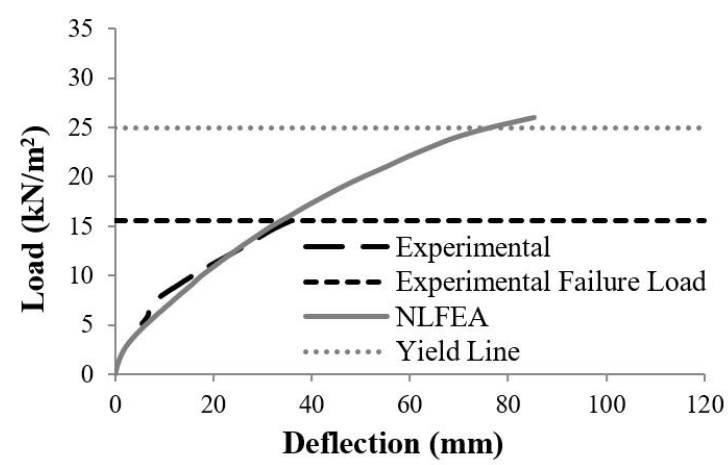

(a)

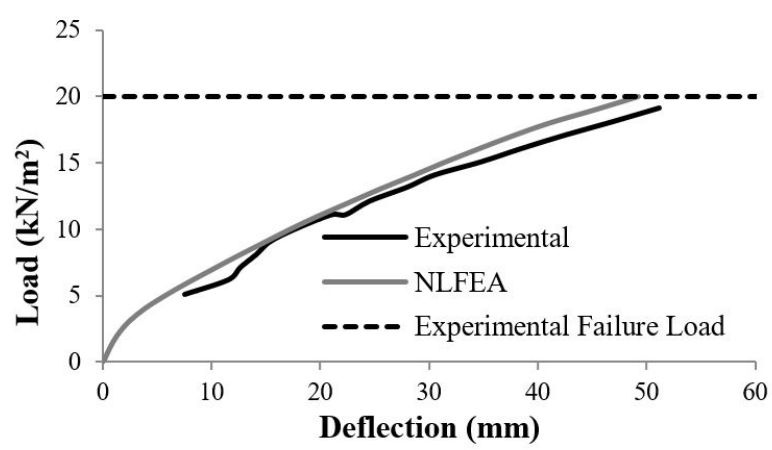

(b)

Figure 6. Comparisons between NLFEA results and experimental data from Sherif's (1996) slab (a) S1 and (b) S2.

In Figure 7, rotations relative to the column for both perpendicular directions on plan are depicted as 'Longitudinal' when calculated from the longitudinal deflected shape, and 'Transverse' (in this case, the transverse rotations are equal to either side of the column due to symmetry), when calculated from the deflected shape along the slab edge (see Figure 5). Previous analysis has already shown that there is no significant difference between extracting the rotations from the shell elements or calculating them from the corresponded deflected shape [25]. 

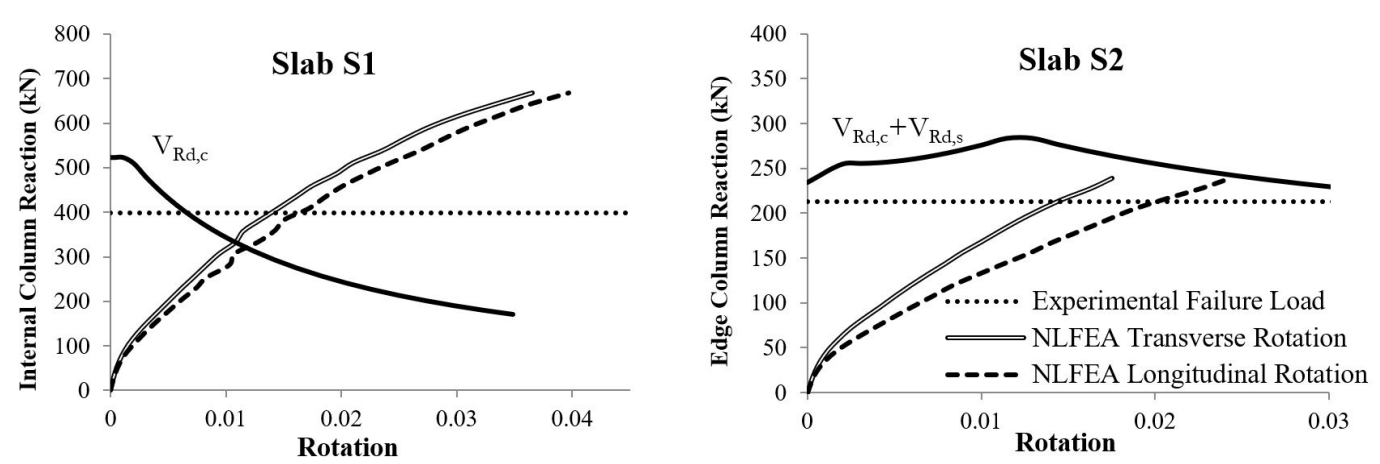

Figure 7.Column reaction-rotation relative to the column for the slabs of Sherif and Dilger [6] and resistance according to the CSCT.

The CSCT is seen to give reasonable predictions for punching failure for the slabs of Sherif and Dilger [6] when adopting a fixed $k_{e}$ ( 0.9 and 0.7 for internal and edge column, respectively). A similar conclusion was found by Soares and Vollum [19], when comparing experimental punching shear failure load with those calculated with the CSCT for both isolated specimens of El-Salakawy et al. [21] and continuous specimens of Regan [20]. The longitudinal direction had the largest rotations, thus critical to calculate punching resistance according to MC2010 for all specimens aforementioned.

\section{SUBASSEMBLY OF DESIGNED SLAB}

A parametric analysis of the flat slab designed in Section 3 was carried out with Diana. The slab was modelled in a series of subassemblies similar to that tested by Sherif and Dilger [6]. The subassembly shown in Figure 8 includes edge column 2A and internal column 2B (refer to Figure 1).

The slab was modelled with eight-node quadrilateral curved shell elements with a size of around $50 \mathrm{~mm}$ square near the slab/column connection, and $150 \mathrm{~mm}$ square elsewhere. Six-node triangular curved shell elements were used to connect the refined mesh to the coarse mesh. The columns were modelled with elastic twenty-node brick elements measuring $150 \times 50 \times 50 \mathrm{~mm}$, and were fully fixed at each end. Although unrealistic, this assumption has no significant influence on the NLFEA results since the columns were modelled elastically, which is representative of the lower levels of a tall building in which the axial column load is sufficient to prevent cracking.

The analysis modelled the full column height of $3.75 \mathrm{~m}$ above and below the slab. The adopted characteristic concrete compressive strength was 30MPa. Symmetry was simulated with only rotational fixities as done for the analysis in Soares and Vollum [34] to avoid any additional in-plane forces.

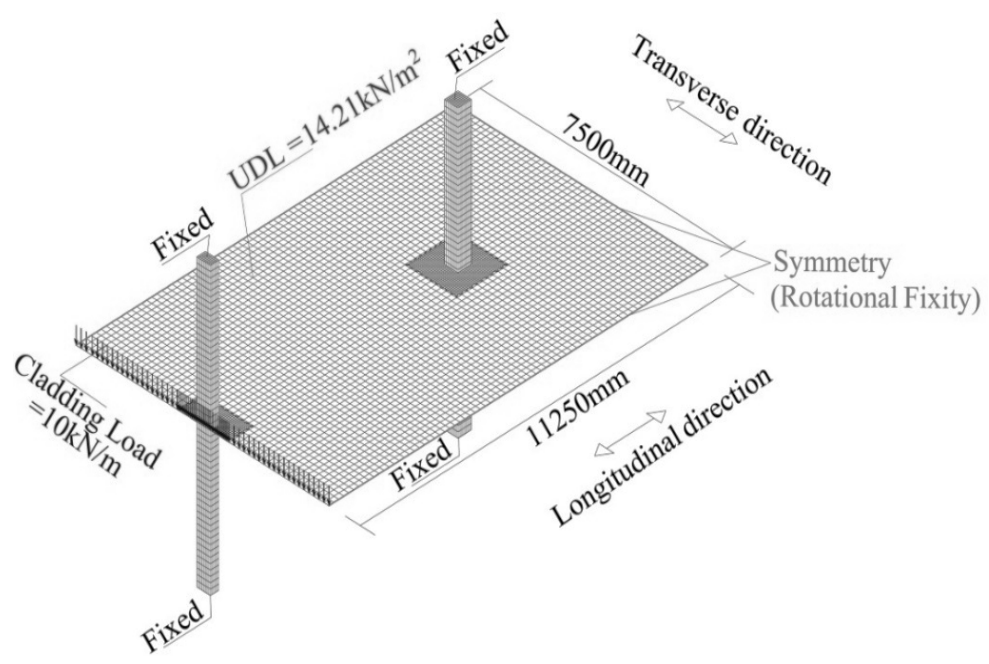

Figure 8. Subassembly of the designed flat slab. 


\subsection{Influence of Reinforcement arrangement}

A parametric study was carried out to investigate the influence of varying the reinforcement in the slab of the subassembly shown in Figure 8. Columns were modelled as elastic and extended $3.75 \mathrm{~m}$ above and below the slab. The ends of the columns were fully fixed. Figure 8 gives further details on the slab dimensions and adopted boundary conditions. The objective was to determine whether the influence of varying the flexural reinforcement in the subassembly was similar to that predicted for slabs with the geometry tested by Regan [20], discussed in Soares and Vollum [19].

Figure 9 and 10 show the baseline reinforcement arrangement used in the subassembly which was determined from analysis of the full slab shown in Figure 1 using the procedure described in Section 3. A minimum reinforcement area of $377 \mathrm{~mm}^{2} / \mathrm{m}$ was provided where no reinforcement is shown, calculated according to EC2. Loads were applied as shown in Figure 8. Both UDL and cladding loads were increased proportionately until failure. This load case is critical for the internal column, but not the edge column where pattern loading consisting of the full factored load on the end of span and factored dead load on the internal span is more critical. The all spans fully loaded load case was adopted since the main objective was to compare the punching resistances given by EC2, NBR 6118 and MC2010 Levels II to IV.

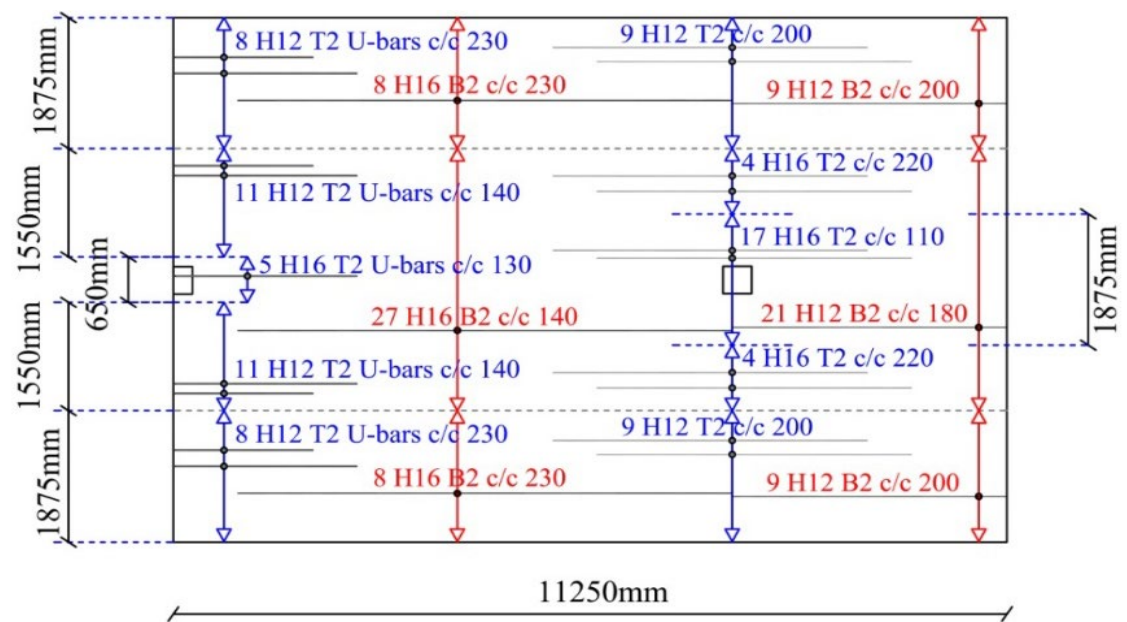

Figure 9. Longitudinal reinforcement designed for the subassembly.

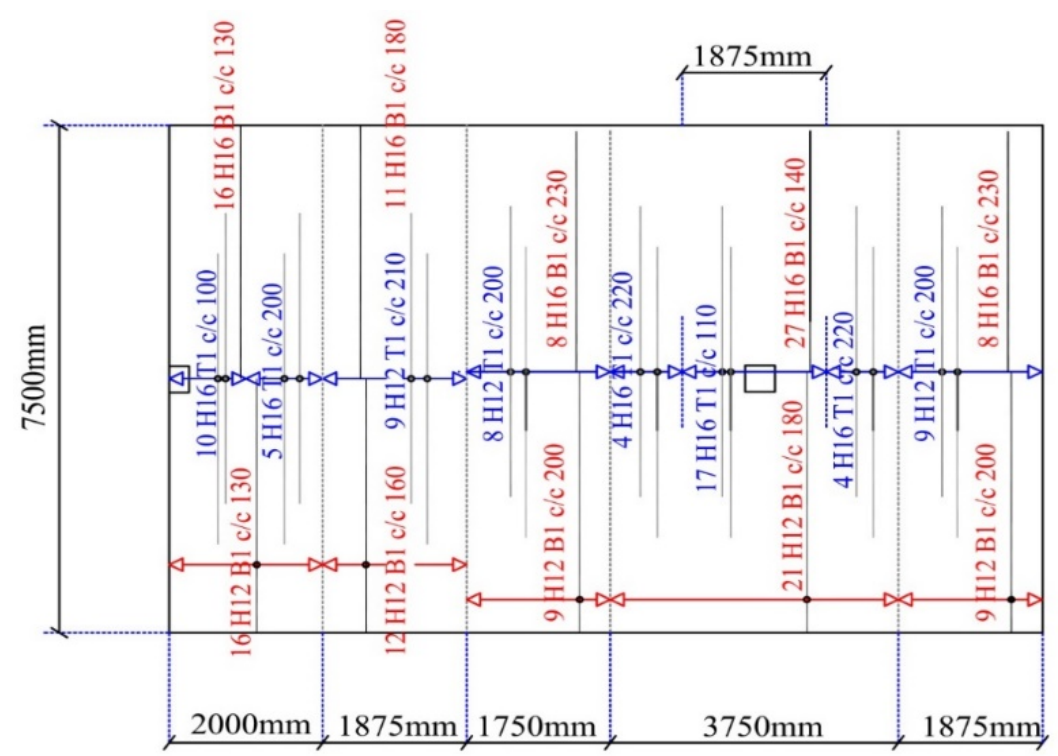

Figure 10. Transverse reinforcement designed for the subassembly. 
In Figure 9, the support reinforcement ratio, normal to the free slab edge, is $\rho_{\text {sup }}=0.8 \%$ over a width of $c_{2}+y$ ( $w h e r e$ $\mathrm{y}$ is the perpendicular distance from the slab edge to the inner column face and $\mathrm{c}_{2}$ is the parallel column dimension). Analyses were also carried out with $\rho_{\text {sup }}$ doubled to $\rho_{\text {sup }}=1.0 \%$ and halved to $\rho_{\text {sup }}=0.5 \%$. The span reinforcement ratio was also doubled from $\rho_{\text {sup }}=0.6 \%$ in to $\rho_{\text {span }}=1.2 \%$, and halved to $\rho_{\text {span }}=0.3 \%$. All nine slabs were loaded with a line load along the short external edge representing cladding. An additional analysis was carried out with reinforcement ratio of $\rho_{\text {sup }}=0.8 \%$ and $\rho_{\text {span }}=0.6 \%$ and no cladding load, making a total of ten analyses. Table 2 gives more details of the slabs.

Table 2. Details on the parametric study varying the reinforcement arrangement.

\begin{tabular}{cc}
\hline$f_{c k}$ & $\mathbf{3 0 ~ M P a}$ \\
\hline$\gamma_{c}$ & 1.5 \\
\hline$f_{y k}$ & $500 \mathrm{MPa}$ \\
\hline$E_{s}$ & $200 \mathrm{GPa}$ \\
\hline$\gamma_{s}$ & 1.15 \\
\hline$d_{1}{ }^{\text {a }}$ & $212 \mathrm{~mm}$ \\
\hline$d_{2}{ }^{\mathbf{b}}$ & $196 \mathrm{~mm}$ \\
\hline Self-weight & $6.25 \mathrm{kN} / \mathrm{m}^{2}$ \\
\hline Superimposed dead load & $1.5 \mathrm{kN} / \mathrm{m}^{2}$ \\
\hline Imposed load & $2.5 \mathrm{kN} / \mathrm{m}^{2}$ \\
\hline Cladding load & $10 \mathrm{kN} / \mathrm{m}$ \\
\hline Edge Column (2A) & $250 \mathrm{~mm} \mathrm{x} \mathrm{400} \mathrm{mm}$ \\
\hline Internal Column (2B) & $400 \mathrm{~mm} \mathrm{x} 400 \mathrm{~mm}$ \\
\hline$k_{e}$ & 0.7 \\
\hline$k_{d g}$ & 0.89 \\
\hline
\end{tabular}

${ }^{\mathrm{a}}$ Top and Bottom bars in the transverse direction. ${ }^{\mathrm{b}}$ Top and Bottom bars in the longitudinal direction.

Figure 11 shows the resulting longitudinal rotations relative to the column, calculated from the longitudinal deflected shape (such as that presented in Figure 6), and the design shear force at the external column extracted from LFEA. The rotations were calculated as previously described.

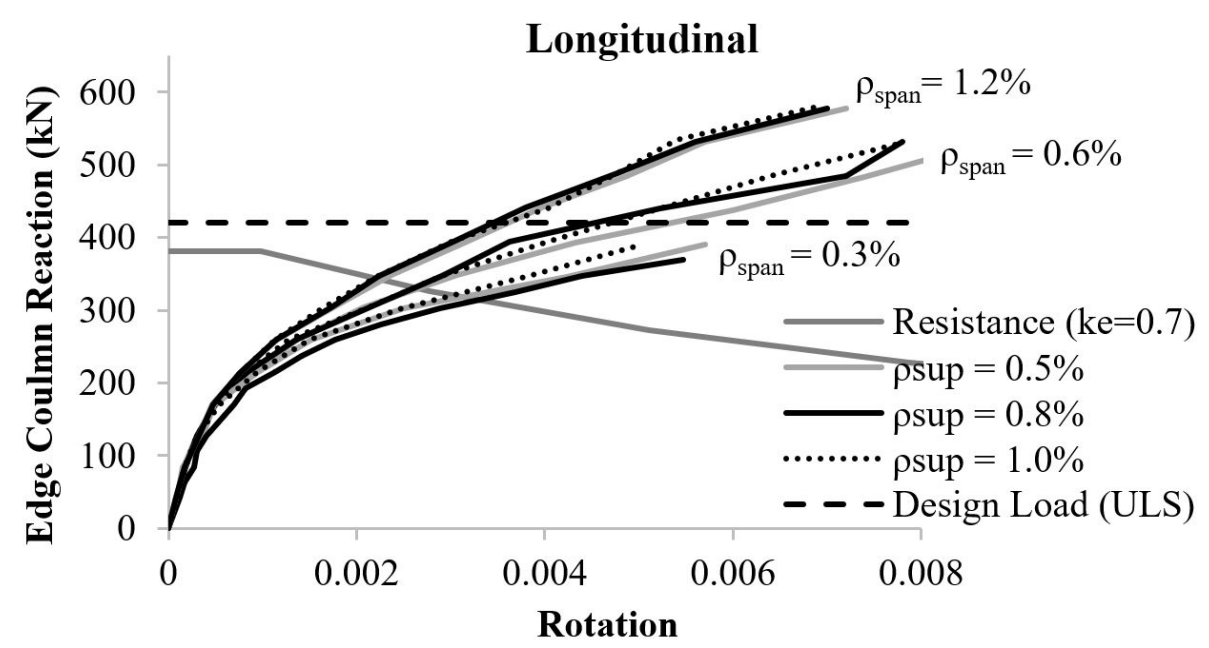

Figure 11. Longitudinal rotation of the subassembly's edge column from the parametric study. 
Figure 11 shows that, as for Regan's [20] slabs (Soares and Vollum [19]), longitudinal span reinforcement is predicted to have significantly greater influence on the longitudinal rotation at edge columns than longitudinal hogging reinforcement at the edge column. Figure 11 also shows the shear resistance provided by the concrete calculated according to MC2010 with $k_{e}=0.7$, chosen on the basis of good results for previous analysis of continuous flat slabs tested by Regan [20] (Soares and Vollum [19]) and Sherif and Dilger [6].

Figure 12 shows that the calculated eccentricity M/V at the edge column increased with load. A similar outcome was observed in the specimens by Regan [20] (Soares [25]) where the increase in eccentricity for the elastic column is explained by its increased stiffness compared to the column in Regan's tests. In MC2010, the basic control perimeter is reduced by a multiple $k_{e}$ to account for loading eccentricity. If $k_{e}$ is calculated with Equation 4 of MC2010, the predicted punching resistance depends on the column flexural stiffness which depends on the column axial load. It is unclear whether this is the case in reality. In the limit, the maximum eccentricity is limited by the maximum moment that can be transferred to the column.

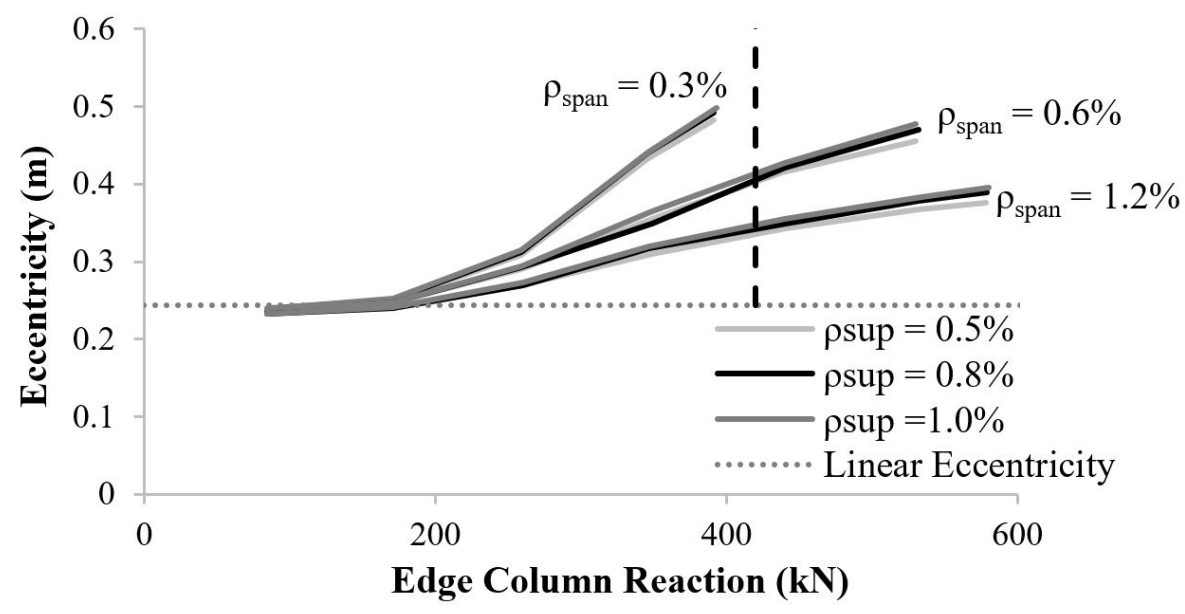

Figure 12. Influence of varying reinforcement arrangement in the eccentricity of the subassembly's edge column.

\section{CODE PREDICTIONS}

This section is used to compare predictions of levels II, III, IV of MC2010, NBR 6118, and EC2, for the slabs considered in the parametric study previously described.

\subsection{Critical direction for rotations}

According to MC2010, the punching resistance depends on the greater of the slab rotations relative to the column in the longitudinal and transverse directions. Soares and Vollum [19] show that longitudinal rotations (i.e. rotations calculated from longitudinal deflections) are critical for the specimens of El-Salakawy et al. [21] and Regan [20] in all cases. This finding is not true in general, and is partly a consequence of the specimen geometry and loading arrangement. Longitudinal rotations are also critical for the tests of Sherif and Dilger [6], but the difference between longitudinal and transverse rotations is much less than for Regan's [20] slabs, since the specimens have slightly more realistic dimensions ratio. The subassembly shown in Figure 8 realistically models the direction of span in both the longitudinal and transverse directions as for the Sherif and Dilger's [6] tests.

For practical slabs, the critical direction can vary and depends on parameters including the reinforcement arrangement and magnitude of the cladding load. Figure 13 compares the longitudinal and transverse rotations with and without cladding load for slab $\rho_{\text {sup }}=0.8 \%$ and $\rho_{\text {span }}=0.6 \%$. The reinforcement is the same for both cases and is designed for the case with cladding. Interestingly, the critical direction for rotations in Figure 13 changes from longitudinal to transverse when the cladding load is included. The resistances in Figure 13 are calculated with Equation 5 and $k_{e}=0.7$. Table 3 summarizes the values of $V_{R d, c}$ calculated at rotations corresponding to the design ULS (Ultimate Limit State) load at the edge column, which was calculated with LFEA. 

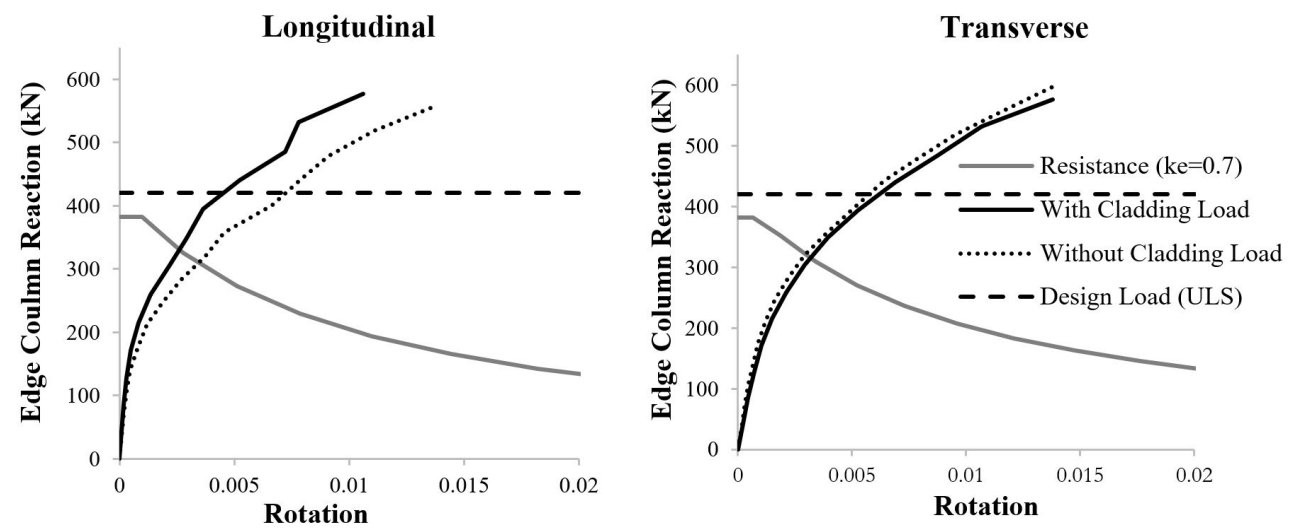

Figure 13. Comparison between longitudinal and transverse rotations with and without cladding loads for $\rho_{\text {sup }}=0.8 \%$ and $\rho_{\text {span }}=0.6 \%$.

Table 3. $V_{R d, c}$ calculated with $k_{e}=0.7$ with and without cladding load.

\begin{tabular}{cccc}
\hline \multirow{2}{*}{ Slabs } & \multicolumn{2}{c}{$\begin{array}{l}\mathbf{V}_{\mathbf{R d}, \mathbf{c}} \\
(\mathbf{k N})\end{array}$} \\
\cline { 2 - 4 } & Longitudinal & Transverse \\
\hline With Cladding Load & 290 & 257 \\
\hline Without Cladding Load & 240 & 260 \\
\hline
\end{tabular}

Figure 14 compares longitudinal and right-hand side transverse rotations (greater than the left-hand side transverse rotation for all cases due to asymmetric transverse reinforcement), relative to the column, for all 9 slabs with cladding load. Also shown is the MC2010 punching resistance provided by the concrete calculated with Equation 5 for $k_{e}=0.7$.

It can be seen in Figure 14 that transverse direction is critical for all cases. Neither the span nor the support longitudinal reinforcement seems to have a significant impact on these transverse rotations, as shown in Figure 15. Longitudinal flexural reinforcement (span/support) have no influence on transverse rotations, as can be seen in Figure 15, though it can still influence punching resistance owing to shear redistribution around the control perimeter, as stated by Sagaseta et al. [35], which suggests that the boundary conditions adopted in punching shear tests could have a greater influence than considered up to now.
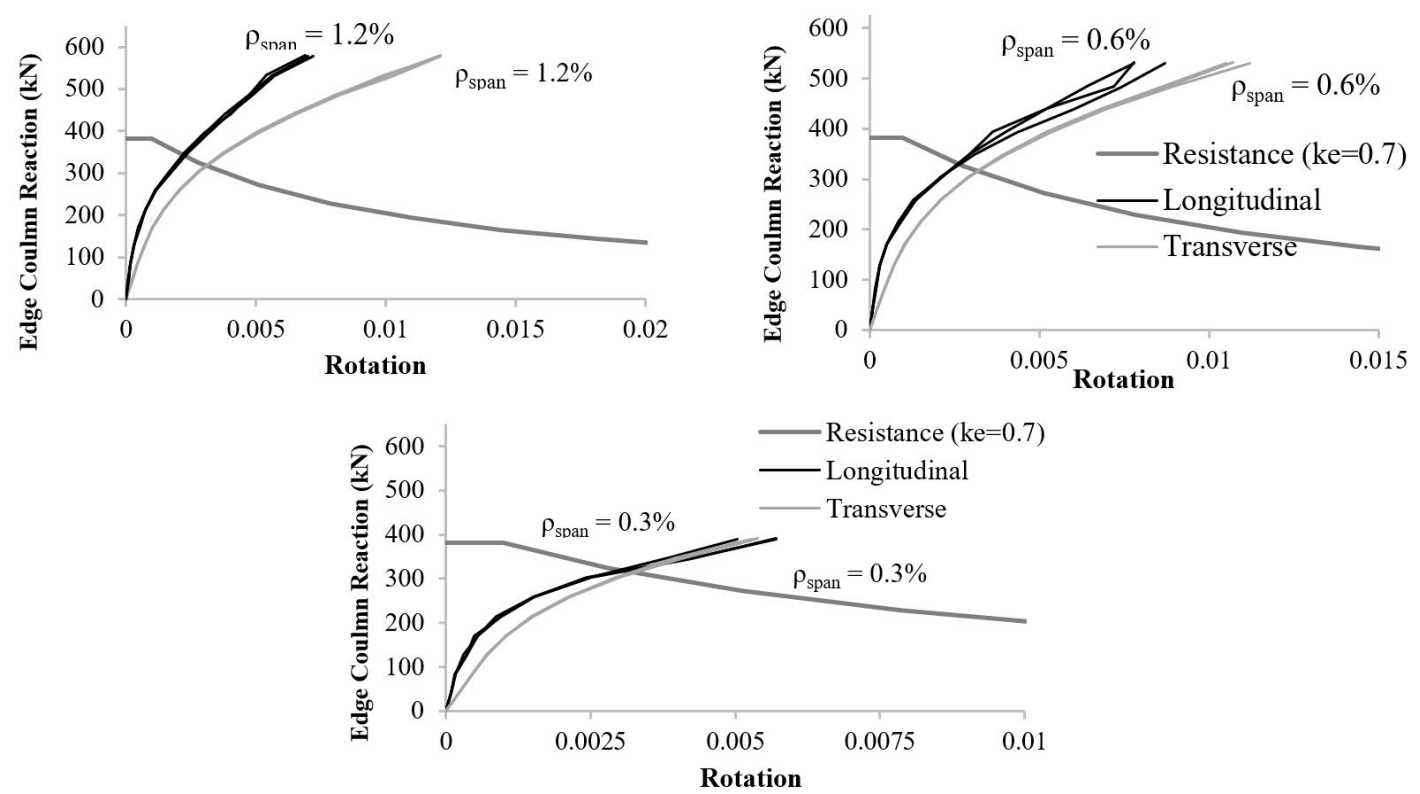

Figure 14. Comparison between longitudinal and transverse rotations for the edge column of the subassembly parametric study. 


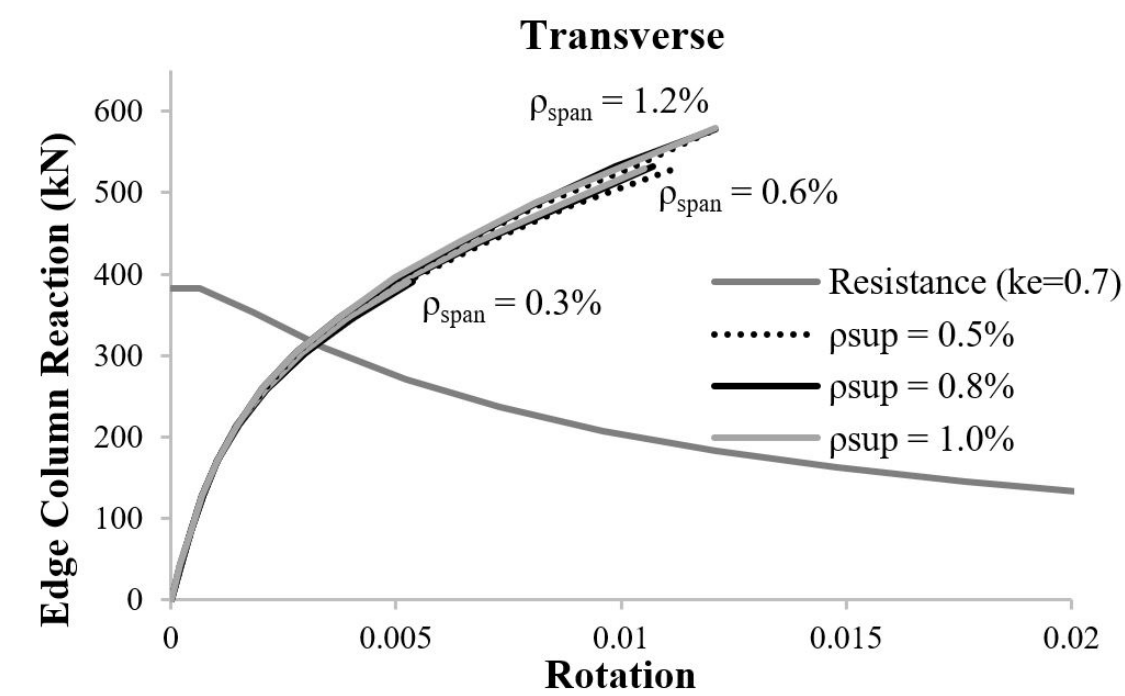

Figure 15. Transverse rotations of the subassembly's edge column from the parametric study.

\subsection{Comparisons between MC2010 Levels II, III, IV, EC2 and NBR6118 for edge columns}

The following section compares the areas of punching shear reinforcement required by the different levels of MC2010, NBR 6118 and EC2 for edge column A2 (refer to Figure 1). The effects of uneven shear were accounted for using the simplified $\beta=1.4$ for EC2 and $k_{e}=0.7$ for MC2010 as allowed for braced frames. NBR 6118 does not allows the use of a fixed value, as stated in section 2.3, so the design stress was calculated based on Equation 12. All three codes adopt partial factor of $\gamma_{s}=1.15$ for reinforcement. For concrete, EC2 and MC2010 adopt $\gamma_{c}=1.5$ and NBR 6118 adopts $\gamma_{c}=1.4 . V_{\text {flex }}$ was calculated with yield line analysis.

For Level III, $m_{s}$ and $r_{s}$ were calculated in each direction with LFEA using the elements and mesh shown in Figure 8. Furthermore, $m_{s}$ also included the twisting moments in accordance with Wood [23]. Figure 16 shows rotations for longitudinal and transverse directions from NLFEA, and calculated with LoA II and III of MC2010. It also shows $V_{R d, c}$ from Equation 1 of EC2, which is similar for NBR 6118, and the resistance curve of Equation 5 from MC2010 using $k_{e}=0.7$ MC2010, NBR 6118 and EC2 need $V_{R d, c}$ to calculate the required amount of shear reinforcement. All three codes were used to design shear reinforcement within a zone of $1.5 \mathrm{~d}$ around the column for the design shear force of $420 \mathrm{kN}$.

MC2010 requires a minimum area of reinforcement to satisfy $V_{R d, s}>0.5 V_{E d}$. This was overlooked for all the LoA IV calculations as it is intended for assessment. Figure 16 also shows the maximum punching resistance, limited by crushing of the concrete struts around the column, $V_{R d, \max }$, from Equation $9\left(k_{s y s}=2.8\right)$. Table 4 shows $V_{R d, c}$ for all LoA of MC2010 in both the longitudinal and transverse directions. The results in bold are the smallest, thus critical according to MC2010. Also shown in Table 4 are $V_{R d, c}$ from Equation 1 of EC2 and NBR 6118, $V_{f l e x}$ from yield analysis, and the shear reinforcement required by each code and LoA for MC2010.

Interestingly, the rotations in the transverse direction calculated with LoA III are slightly greater than LoA II. This is believed to be the result of the elastic shell elements overestimating torsion at the side of the column, which led to a greater $m_{s}=\left|M_{y y}\right|+\left|M_{x y}\right|$, and consequently greater rotations. Shear reinforcement requirements for LoA III almost double as a result of the transverse direction becoming critical. This issue merits further studies as reducing torsion stiffness in a LFEA of a shell-based model potentially reduces transverse rotations, but may affect rotations in the longitudinal direction.

As can be seen in Figure 16 and Table 4, the critical direction varies with the level of approximation. Figure 13 and Table 3 shows that the omission of cladding load in the NLFEA swapped the critical direction from transverse to longitudinal, which led to a slightly greater amount of shear reinforcement required according to MC2010 LoA IV (refer to Table 4). 
In most of the LoA II and III designs, the design shear force is very close to the maximum possible shear capacity which is limited by crushing of concrete near the support region according to MC2010's limit of $k_{s y s}=2.8$ for double headed studs. For LoA II, the assumption of $r_{s}=0.22 L$ significantly overestimated the rotations for the analysis. LFEA suggests that the point of contraflexure is actually closer to $r_{s}=0.15 \mathrm{~L}$ in the longitudinal direction and $r_{s}=0.18 \mathrm{~L}$ in the transverse, which would result in smaller rotations. The overestimation of torsion from shell element-based models is enough to explain the poor performance of LoA III, as previously discussed. Analysis with LoA IV indicates that concrete crushing failure is not critical in reality for these slabs and that shear failure could be avoided through the provision of shear reinforcement as allowed by the UK National Annex to EC2 which limits $V_{R, \max }$ to $2 V_{R d, c}$.

Though slabs with $\rho_{\text {span }}=0.3 \%$ would likely fail in flexure as suggested by $V_{\text {flex }}$ from Yield Line, and NLFEA, which stopped before the design load could be reached, they are included in Figure 17 for comparative purposes.
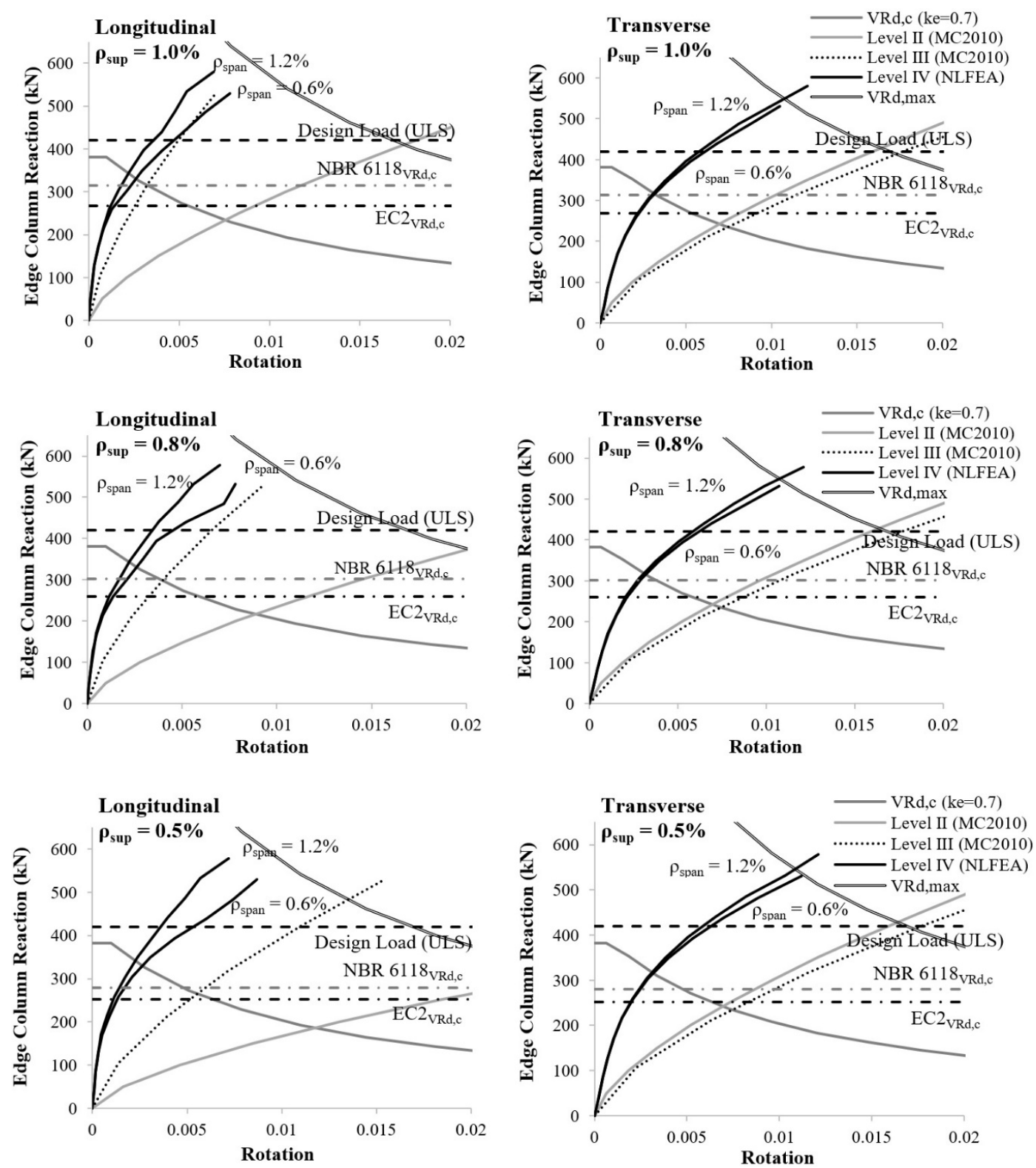

Figure 16. Longitudinal and Transverse rotations of the subassembly slabs from the parametric study. Note: Slabs with $\rho_{\text {span }}=0.3 \%$ didn't reach the design load as would likely fail in flexure, therefore they are not shown in the figure. 
Table 4. $V_{R d, c}$ and $\sum_{1.5 d_{v}} A_{s w}$ from MC2010 LoA II to IV, EC2, NBR6118, and $V_{f l e x}$. Shear forces in $\mathrm{kN}$.

\begin{tabular}{|c|c|c|c|c|c|c|c|c|c|c|c|}
\hline & \multicolumn{6}{|c|}{ MC2010 } & \multirow{3}{*}{\multicolumn{2}{|c|}{ EC2 }} & \multirow{3}{*}{\multicolumn{2}{|c|}{ NBR 6118}} & \\
\hline & \multicolumn{6}{|c|}{$\mathbf{k}_{\mathrm{e}}=\mathbf{0 . 7}$} & & & & & \\
\hline & \multicolumn{3}{|c|}{ Longitudinal/Transverse } & \multicolumn{3}{|c|}{$\sum_{1.5 d_{v}} A_{s w}\left[\mathbf{m m}^{2}\right]$} & & & & & \\
\hline & LoA IV & LoA III & LoA II & LoA IV & LoA III & LoA II & $V_{R d, c}$ & $\begin{array}{l}\sum_{1.5 d_{v}} A_{s w} \\
{\left[\mathbf{m m}^{2}\right]}\end{array}$ & $V_{R d, c}$ & $\begin{array}{l}\sum_{1.5 d_{v}} A_{s w} \\
{\left[\mathbf{m m}^{2}\right]}\end{array}$ & $V_{f l e x}$ \\
\hline$\rho_{\text {sup }}=1.0 \%$ & \multirow{2}{*}{ - } & \multirow{4}{*}{$274.44 / 144.22$} & \multirow{4}{*}{$142.94 / 155.48$} & \multirow{2}{*}{-} & \multirow{4}{*}{1358.52} & \multirow{4}{*}{1364.83} & \multirow{4}{*}{267.98} & \multirow{4}{*}{1107.72} & \multirow{4}{*}{313.97} & \multirow{4}{*}{1091.32} & \multirow{2}{*}{424.77} \\
\hline$\rho_{\text {span }}=0.3 \%$ & & & & & & & & & & & \\
\hline $\begin{array}{l}\rho_{\text {sup }}=1.0 \% \\
\rho_{\text {span }}=0.6 \%\end{array}$ & $285 / 260$ & & & $788.18^{b}$ & & & & & & & 546.37 \\
\hline $\begin{array}{l}\rho_{\text {sup }}=1.0 \% \\
\rho_{\text {span }}=1.2 \%\end{array}$ & $310 / 262$ & & & $778.33^{\mathrm{b}}$ & & & & & & & 759.68 \\
\hline $\begin{array}{l}\rho_{\text {sup }}=0.8 \% \\
\rho_{\text {span }}=0.3 \%\end{array}$ & - & \multirow{2}{*}{$246.43 / 144.22$} & \multirow{4}{*}{$\mathbf{1 1 7 . 8 0} / 155.48$} & - & \multirow{2}{*}{1358.52} & \multirow{4}{*}{1488.67} & \multirow{4}{*}{260.09} & \multirow{4}{*}{1132.20} & \multirow{4}{*}{301.81} & \multirow{4}{*}{1126.4} & 420.69 \\
\hline $\begin{array}{l}\rho_{\text {sup }}=0.8 \% \\
\rho_{\text {span }}=0.6 \%\end{array}$ & $290 / 257$ & & & $802.96^{\mathrm{b}}$ & & & & & & & 542.29 \\
\hline $\begin{array}{l}{ }^{\mathrm{a}} \rho_{\text {sup }}=0.8 \% \\
\rho_{\text {span }}=0.6 \%\end{array}$ & $240 / 260$ & $254.95 / \mathbf{1 7 2 . 5 5}$ & & $886.70^{\mathrm{b}}$ & 1218.97 & & & & & & 542.29 \\
\hline $\begin{array}{l}\rho_{\text {sup }}=0.8 \% \\
\rho_{\text {span }}=1.2 \%\end{array}$ & $315 / 262$ & $246.43 / 144.22$ & & $778.33^{b}$ & 1358.52 & & & & & & 755.61 \\
\hline $\begin{array}{l}\rho_{\text {sup }}=0.5 \% \\
\rho_{\text {span }}=0.3 \%\end{array}$ & 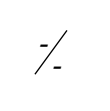 & & & - & & & & & & & 414.34 \\
\hline $\begin{array}{l}\rho_{\text {sup }}=0.5 \% \\
\rho_{\text {span }}=0.6 \%\end{array}$ & $275 / 255$ & $192.74 / \mathbf{1 4 4 . 2 2}$ & $79.59 / 155.48$ & $812.81^{\mathrm{b}}$ & 1358.52 & 1676.90 & 252.21 & 1153.62 & 279.71 & 1190.19 & 535.95 \\
\hline $\begin{array}{l}\rho_{\text {sup }}=0.5 \% \\
\rho_{\text {span }}=1.2 \%\end{array}$ & $309 / 262$ & & & $778.33^{\mathrm{b}}$ & & & & & & & 749.25 \\
\hline
\end{tabular}

${ }^{\mathrm{a}}$ Without Cladding Load. ${ }^{\mathrm{b}}$ Smaller than the minimum reinforcement by MC2010 corresponding to $V_{R d, s}>0.5 V_{E d}\left(1034.48 \mathrm{~mm}{ }^{2}\right)$.

Figure 17 compares the amount of shear reinforcement within a zone of $1.5 \mathrm{~d}$ around the column in relation to the longitudinal span reinforcement for all slabs with cladding load. According to MC2010 LoA II, III, NBR 6118, and EC2, the required area of punching shear reinforcement is independent of the span reinforcement ratio. However, Figure 17 shows that even though LoA IV captures the influence of span reinforcement, the impact on required shear reinforcement is minimal, especially for slabs with $\rho_{\text {sup }}=1.0 \%$. This is so since transverse rotations are critical for the considered slabs, which is not always the case.

The impact of longitudinal support reinforcement is significantly greater for LoA II of MC2010 than LoA III and IV, NBR 6118, or EC2. Both LoA II and III, which are intended for design, required significantly more punching shear reinforcement than NBR 6118, and in some cases double the reinforcement required by LoA IV, which is intended for assessment. LoA IV requirements are very close to those of EC2 when the minimum reinforcement rule of MC2010 is implemented. 


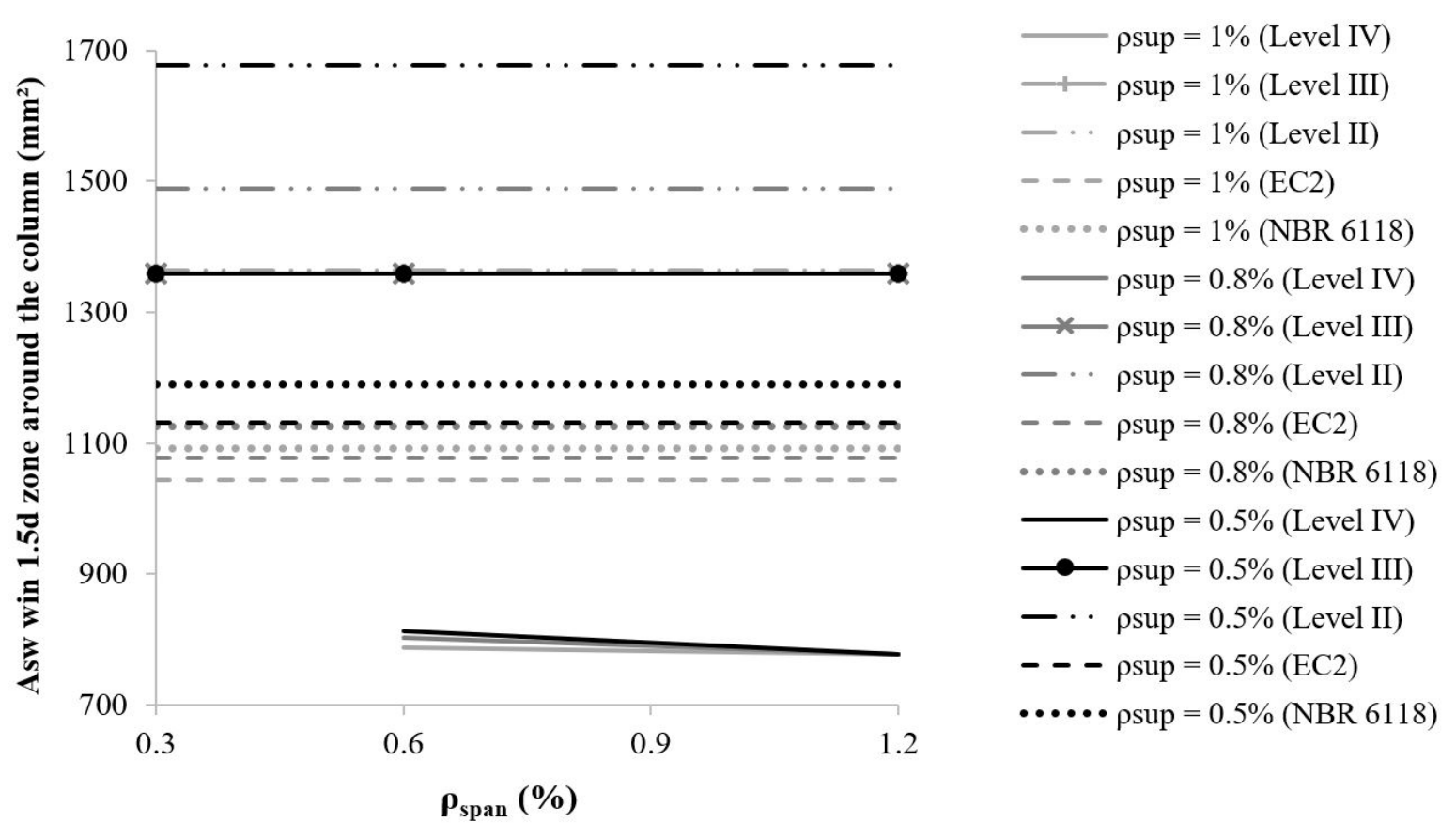

Figure 17. Shear reinforcement in 1.5d from the column required by MC2010, EC2 and NBR6118.

\section{CONCLUSIONS}

This paper investigated the impact of slab continuity through modelling assumptions, critical directions of rotations and code comparison on the punching resistance of an edge column from realistically proportioned flat slab floor plates. Elastic columns were considered in the punching shear assessments of the full-scale slab to simplify the analysis. The effect of this was to increase the moment transferred to the edge column but also to reduce longitudinal slab rotations calculated with NLFEA which were generally not critical for the considered slabs.

The increase in $\mathrm{M} / \mathrm{V}$ with load, due to moment redistribution from span to support, presented in Figure 12 has little impact on the reactions at edge columns, as stated by Soares [25]. The reason being that edge column moment is relatively small compared with that at internal support. The parameter that characterizes the eccentricity by the MC2010, $k_{e}$, can be calculated according to Equation 4, therefore, different modelling assumptions can influence the moment transferred to the column, which leads to different values of $k_{e}$. In accordance to Soares and Vollum [19] the use of the constant parameter $k_{e}=0.7$, recommended by MC2010 for edge columns, leads to reasonable results, justifying its use during the analysis. The average moment $m_{s}$ to be adopted in MC2010 LoA III, which is calculated from LFEA with shell elements, requires further study since it depends on the shear modulus adopted in the analysis.

For the modelled full-scale flat slabs, longitudinal span reinforcement has a significantly greater impact on longitudinal rotations than longitudinal support reinforcement at the slab edge (Figure 11) as for Regan's [20] specimens. The direction of greatest rotation varies with reinforcement arrangement and between the LoA in MC2010. However, the longitudinal reinforcement could still affect punching resistance due to shear redistribution around the control perimeter of the type proposed by Sagaseta et al. [35] for slabs with non-axis-symmetrical reinforcement. The impact on punching resistance was significantly less than observed for Regan's specimens [20], partly because transverse rotations are critical for all cases. The analyses carried out in accordance with EC2, NBR 6118 and MC2010 LoA II and LoA III showed that results for punching shear reinforcement are independent of the longitudinal span reinforcement, unlike the results obtained with MC2010 LoA IV, which is capable of capturing the influence of continuity and flexural reinforcement ratio in the span. For the considered full-scale slab, the area of shear reinforcement required within $1.5 d$ of the column face by MC2010 LoA IV is around 35\% less than that by NBR 6118 and EC2. In some cases, the area of shear reinforcement required by MC2010 LoA IV is around half that required by LoA II and III, which are over conservative due to slab rotations being overestimated. 


\section{REFERENCES}

[1] S. Kinnunen and H. Nylander, Punching of Concrete Slabs Without Shear Reinforcement (Transactions of the Royal Institute of Technology 158). Stockholm, Sweden: Royal Institute of Technology , 1960, 112 p.

[2] Fédération International du Béton, Punching of Structural Concrete Slabs (fib Bulletin 12), 2001.

[3] A. N. Talbot, Reinforced Concrete Wall Footings and Column Footings (Bulletin 67). Illinois: Engineering Experiment Station, University of Illinois, 1913.

[4] C. E. Broms, "Punching of flat plates - tangential strain theory for punching failure of flat slabs," ACI Struct. J., vol. 113, pp. 95-104, Jan-Feb 2016, http://dx.doi.org/10.14359/51687942.

[5] L. C. Hoang and A. Pop, "Punching shear capacity of reinforced concrete slabs with headed shear studs," Mag. Concr. Res., vol. 68, no. 3, pp. 118-126, 2016, http://dx.doi.org/10.1680/macr.15.00033.

[6] A. G. Sherif and W. H. Dilger, "Tests of full-scale continuous reinforced concrete flat slabs," ACI Struct. J., vol. 97, no. 3, pp. 455467, 2000.

[7] P. S. Chana and S. B. Desai, "Membrane action, and design against punching shear," Struct. Eng., vol. 70, no. 19, pp. 339-343, 1992.

[8] A. G. Sherif, "Behaviour of reinforced concrete flat slabs”, Ph.D. dissertation, Dept. Civ. Eng., Univ. Calgary, Calgary, Alberta, 1996.

[9] J. Einpaul, F. Brantschen, M. Fernández Ruiz, and A. Muttoni, "Performance of punching shear reinforcement under gravity loading: influence of type and detailing," ACI Struct. J., vol. 113, no. 4, pp. 827-838, Jul-Aug 2016, http://dx.doi.org/10.14359/51688630.

[10] R. L. Vollum, T. Abdel-Fattah, M. Eder, and A. Y. Elghazouli, "Design of ACI-type punching shear reinforcement to Eurocode 2," Mag. Concr. Res., vol. 62, no. 1, Jan 2010, http://dx.doi.org/10.1680/macr.2008.62.1.3.

[11] A. Muttoni, "Punching shear strength of reinforced concrete slabs without transverse reinforcement," ACI Struct. J., vol. 105, no. 4, pp. 440-450, Jul-Aug 2008. [Online]. Available: https://infoscience.epfl.ch/record/116123

[12] J. Moe, Shearing Strength of Reinforced Concrete Slabs and Footings under Concentrated Loads (Development Department Bulletin D47). Skokie, IL: Portland Cement Association, 1961, pp. 130.

[13] M. Fernández Ruiz and A. Muttoni, "Applications of critical shear crack theory to punching of reinforced concrete slabs with transverse reinforcement," ACI Struct. J., vol. 106, no. 4, pp. 485-494, 2009. [Online]. Available: https://infoscience.epfl.ch/record/134716

[14] Fédération International du Béton, Model Code for Concrete Structures 2010, 2013.

[15] M. P. Ferreira, G. S. Melo, P. E. Regan, and R. L. Vollum, "Punching of reinforced concrete flat slabs with double-headed shear reinforcement," ACI Struct. J., vol. 111, no. 2, pp. 363-374, 2014., http://dx.doi.org/10.14359/51686535.

[16] A. Dönmez and Z. P. Bažant, "Critique of critical shear crack theory for fib Model Code articles on shear strength and size effect of reinforced concrete beams," Struct. Concr., vol. 20, pp. 1451-1463, 2019., http://dx.doi.org/10.1002/suco.201800315.

[17] Associação Brasileira de Normas Técnicas, Projeto de Estruturas de Concreto, NBR 6118, 2014.

[18] British Standards Institution, Eurocode 2, Design of Concrete Structures - Part 1-1 - General Rules and Rules for Buildings, BS EN 1992-1-1:2004, 2004.

[19] L. F. S. Soares and R. L. Vollum, "Influence of continuity on punching resistance at edge columns," Mag. Concr. Res., vol. 68, no. 23, pp. 1225-1239, 2016, http://dx.doi.org/10.1680/jmacr.16.00052.

[20] P. E. Regan, Tests of Connections Between Flat Slabs and Edge Columns. London: Sch. Archit. Eng., Univ. Westminster, 1993.

[21] E. F. El-Salakawy, M. A. Polak, and M. H. Soliman, "Reinforced concrete slab-column edge connections with shear studs," Can. J. Civ. Eng., vol. 27, no. 2, pp. 338-348, 1998.

[22] The Institution of Structural Engineers, Standard Method of Detailing Structural Concrete ISE, 2006.

[23] R. H. Wood, "The reinforcement of slabs in accordance with a pre-determined field of moments," Concrete (Lond.), vol. 2, no. 2, pp. 69-76, 1968.

[24] British Standards Institution, UK National Annex to Eurocode 2 - Design of Concrete Structures - General Rules and Rules for Buildings, EN 1992-1-1:2004, 2004.

[25] L. F. S. Soares, "Influence of slab continuity on punching resistance,” Ph.D. dissertation, Imp. Coll. London, London, 2017.

[26] A. G. Sherif, “Behaviour of reinforced concrete flat slabs,” Ph.D. dissertation, Dep. Civ. Eng., Calgary, Alberta, 1996.

[27] TNO Diana BV, Finite-element Analysis User's Manual - Release 9.6. TNO Diana BV, 2014.

[28] R. L. Vollum and U. L. Tay, "Modelling tension stiffening in reinforced concrete with NLFEA," Concrete, vol. 41, no. 1, pp. 40-41, 2007.

[29] M. Suidan and W. C. Schnobrich, "Finite element analysis of reinforced concrete," J. Struct. Div., vol. 99, no. 10, pp. 2109-2122, 1973. 
[30] J. Sagaseta, "The influence of aggregate fracture on the shear strength of reinforced concrete beams," Ph.D. dissertation, Imp. Coll. London, London, 2008.

[31] L. M. Trautwein, "Punção em lajes cogumelo de concreto armado: análise experimental e numérica," Ph.D. dissertation, Esc. Politéc., Univ. São Paulo, São Paulo, 2006.

[32] E. Thorenfeldt, A. Tomaszewicz, and J. J. Jensen, "Mechanical properties of high-strength concrete and applications in design," in Proc. Symp. Utilization of High-Strength Concr., Norway, 1987.

[33] F. J. Vecchio and M. P. Collins, "Compression response of cracked reinforced concrete," J. Struct. Eng., vol. 119, no. 12, pp. 35903610, 1993, http://dx.doi.org/10.1139/190-082.

[34] L. F. S. Soares and R. L. Vollum, "Comparison of punching shear requirements in BS8110, EC2 and MC2010," Mag. Concr. Res., vol. 67, no. 24, pp. 1315-1328, 2015, http://dx.doi.org/10.1680/macr.14.00432.

[35] J. Sagaseta, A. Muttoni, M. F. Ruiz, and L. Tassinari, "Non-axis-symmetrical punching shear around internal columns of RC slabs without transverse reinforcement," Mag. Concr. Res., vol. 63, no. 6, pp. 441-457, 2011, http://dx.doi.org/10.1680/macr.10.00098.

Author contributions: FGBSO: data curation, editing, formal analysis, methodology, writing, review, validation. LFSS: data curation, formal analysis, funding acquisition, investigation, methodology, review, software, validation, writing. RLV: conceptualization, project administration, resources, review, supervision.

Editors: Leandro Mouta Trautwein, José Luiz Antunes de Oliveira e Sousa, Guilherme Aris Parsekian. 